\title{
Co-targeting the EGFR and IGF-IR with anti-EGFR monoclonal antibody ICR62 and the IGF-IR tyrosine kinase inhibitor NVP-AEW541 in colorectal cancer cells
}

\author{
MATTHEW P. CUNNINGHAM ${ }^{1}$, HILARY THOMAS ${ }^{1}$, CHRISTOPHER MARKS ${ }^{2}$, MARGARET GREEN ${ }^{2}$, \\ ZHEN FAN $^{3}$ and HELMOUT MODJTAHEDI ${ }^{1,4}$ \\ ${ }^{1}$ Division of Oncology, Postgraduate Medical School, Guildford, ${ }^{2}$ Colorectal unit, Royal Surrey County Hospital, \\ Guildford, UK; ${ }^{3}$ Department of Experimental Therapeutics, The University of Texas M.D. Anderson Cancer Center, \\ Houston, TX, USA; ${ }^{4}$ School of Life Sciences, Kingston University London, Kingston-upon-Thames, UK
}

Received July 29, 2008; Accepted September 9, 2008

DOI: 10.3892/ijo_00000100

\begin{abstract}
The aberrant expression of the epidermal growth factor receptor (EGFR) has been reported in a wide range of epithelial tumours. In some studies, co-expression of insulinlike growth factor receptor-I (IGF-IR) have been associated with resistance to the EGFR inhibitors. Here, we investigated the sensitivity of a panel of human colorectal tumour cell lines, including two newly established lines Colo2 and Colo13, to treatment with anti-EGFR mAb ICR62 and IGF-IR tyrosine kinase inhibitor NVP-AEW541 alone and in combination. We also determined the association between the expression levels of EGFR and IGF-IR with their responses to ICR62 and/or NVP-AEW541. In contrast to DiFi cells, which contained high levels of EGFR but lower level of IGF-IR, the remaining 11 colorectal tumour cells expressed low levels of both EGFR and IGF-IR and such cells were relatively resistant to ICR62 or NVP-AEW-541 when used alone. Interestingly, compared to the results with the single agent, the effect of combination of NVP-AEW541 and ICR62 was found to be additive on inhibiting the growth of Colo13, CCL235, CCL244 cells but antagonistic in other (CCL218) cells. While overexpression of the EGFR seems to be associated with response to ICR62, no clear correlation was found between the expression levels of EGFR and IGF-IR, or the levels of phosphorylated EGFR and response to treatment with NVP-AEW541, in single or combination setting with ICR62. Our results suggest that combining EGFR and IGF-IR inhibitors may enhance antitumour response in a fraction of colorectal cancer cells and warrants further study in colorectal cancer.
\end{abstract}

Correspondence to: Dr Helmout Modjtahedi, School of Life Sciences, Kingston University London, Kingston-upon-Thames, Surrey KT1 2EE, UK

E-mail: h.modjtahedi@kingston.ac.uk

Key words: epidermal growth factor receptor, insulin-like growth factor receptor-I, ICR62, NVP-AEW541, colorectal cancer

\section{Introduction}

Despite continued advances in early diagnosis and improvements of new treatments, colorectal cancer remains one of the most common types of human cancer in terms of incidence and mortality. In 2000, there were 945,000 cases of colorectal cancer and colorectal cancer was responsible for 492,000 deaths worldwide (1).

Over the past three decades, aberrant expression of cell surface receptors with intrinsic protein tyrosine kinase activity has been found in a wide range of epithelial tumours including colorectal cancers, and, in some cases, it has been shown to correlate with poor prognosis. The insulin-like growth factor (IGF) receptor (IGF-IR) is a receptor tyrosine kinase that transmits the mitogenic signals of IGF-I and IGF-II (2-4). Binding of IGF-I or IGF-II to the cysteine-rich extracellular IGF-IR $\alpha$ subunits causes a conformational change in the intracellular domain of the IGF-IR $\beta$-subunits, leading to activation of intrinsic receptor tyrosine kinase and subsequent receptor tyrosine autophosphorylation and phosphorylation of the insulin receptor substrate molecules (e.g. IRS-1, IRS-2) that triggers a cascade of mitogenic cell signal activation via the PI-3K/Akt pathway and via the Ras-Raf-MAPK pathway (2-6).

Deregulation of signalling via the IGF-IR and/or its ligands has been associated with initiation and maintenance of the transformed phenotype, including cell invasion and motility, tumour angiogenesis and metastases, protection against tumour micro-environmental stress, and resistances to chemotherapy and radiotherapy (7-12). Expression of the IGF-IR is found in many types of malignancy including colorectal cancers (13-17). Consequently, therapeutic strategies targeting the IGF-IR have been explored, including the use of mAbs, TKIs, and anti-sense oligonucleotides, which can inhibit the growth of IGF-IR expressing tumour cells (e.g. breast, lung, multiple myeloma) in vitro and in vivo, and enhance responses of cultured or xenografted human cancer cells to treatments with cytotoxic drugs or radiotherapy $(9,18-24)$.

Ample evidence has shown that the IGF-IR cross-talks with other growth factor tyrosine kinase receptors, such as the EGFR, VEGFR, and HER-2, to coordinate the malignant 
behaviour of cancer cells (25-30). IGF-IR expression has also been associated with resistance to anti-EGFR and anti-HER-2 based therapies in several experimental models, and co-targeting the IGF-IR with the EGFR or HER-2 may achieve better therapeutic effects in several types of cancer model (31-33). We have recently reported that the IGF-IR, EGFR, and HER-2 are co-expressed in $75 \%$ of patients with Dukes' C (stage III) colorectal cancer and that targeting of the EGFR in human colorectal tumour cells by a combination of ICR62 and gefitinib was not superior to the result of either agent alone $(17,34)$. The aim of the present study was therefore to examine the cell surface expression of the IGFIR and EGFR in a panel of human colorectal cancer cell lines, including 2 new cell lines recently established in our laboratory, and to evaluate the sensitivity of these cancer cells to treatment with an IGF-IR tyrosine kinase inhibitor (TKI), NVP-AEW541 (35) and our anti-EGFR mAb ICR62 (36). We explored the therapeutic advantage of a combination of ICR62 and NVP-AW541 over the single inhibitor together with the relationship between receptor expression and growth inhibition by the EGFR and/or IGF-IR inhibitors.

\section{Materials and methods}

Cancer cell lines. The human colorectal cancer cell line CCL247/HCT-116 was purchased from the European Collection of Cell Culture (ECCAC; Porton Down, UK), and other colorectal cancer cell lines CCL218/HT-29, CCL221/DLD-1, CCL225/HCT-15, CCL227/SW620, CCL228/SW480, CCL231/SW48, CCL235/SW837, CCL244/ HCT-8/HRT-18 were purchased from The American Type Culture Collection (Manassas, VA, USA). Two new human colorectal tumour cell lines Colo2 and Colo13 were recently established in our laboratory: the Colo2 cell line was established from a patient with a Dukes' A moderately differentiated tumour following a 1-week pre-operative therapy, whereas Colo13 was established from a patient with a Dukes' $\mathrm{C}$ invasive and moderatively differentiated tumour. The EGFR-overexpressing DiFi colorectal cell line was previously reported (34). Other reference human cancer cell lines used in this study included SKBR3 (breast), MCF-7 (breast) and HN5 (head and neck) cells, which overexpress the HER-2, IGF-IR, and EGFR, respectively (34,36-39). All cell lines were cultured in Dulbecco's modified Eagle's medium (DMEM; Sigma-Aldrich, Company Ltd., Dorset, UK), supplemented with $10 \%$ foetal calf serum (FCS; GIBCO Cell Culture Systems, Invitrogen Ltd., Paisley, UK), penicillin $(50 \mu \mathrm{g} / \mathrm{ml})$, streptomycin $(50 \mu \mathrm{g} / \mathrm{ml})$, and neomycin $(100 \mu \mathrm{g} / \mathrm{ml})(\mathrm{GIBCO})$, and were maintained at $37^{\circ} \mathrm{C}$ in a humidified atmosphere with $5 \% \mathrm{CO}_{2}$ as described previously (34).

Reagents. The rat mAb ICR62 (IgG2b) and the mouse mAb HM43.16B were raised against the external domain of the EGFR on the breast carcinoma cell line MDA-MB468 and the HC2 20d2/c cell line, respectively (36, unpublished data). The mouse anti-IGF-IR antibody ( $\alpha$ subunit) was purchased from Calbiochem (Merck Biosciences Ltd., Nottingham, UK). The mouse anti-EGFR mAb clone F4 and rabbit anti B-actin polyclonal antibody were purchased from Sigma
(Sigma-Aldrich). Antibodies to phospho-tyrosine (P-Tyr100), Tyr1068-phosphorylated EGFR, and Thr202/Tyr204phosphorylated MAPK p44/p42 were purchased from New England Biolabs Ltd. (Hitchin, UK). Antibodies to phosphorylated EGFR in other sites (Tyr1173, 1148, 1086, and 845), and Ser473-phosphoryalted Akt were purchased from Biosource (Biosource Europe S.A., Belgium). The FITCconjugated goat anti-mouse IgG secondary antibody was purchased from Southern Biotechnology Associates Inc. (AL, USA). The IGF-IR TKI NVP-AEW541 was kindly provided by Novartis (35) and the inhibitors to PI3K (LY294002) and MEK (U0126) were purchased from Sigma. EGF and HBEGF were from R\&D Systems, MN, USA, whereas IGF-I and IGF-II were from Austral Biologicals, CA, USA.

Flow cytometric analysis. The cell surface levels of EGFR or IGF-1R were determined using FACS analysis as described previously (34). A minimum of 10,000 events were recorded by excitation with an argon laser at $488 \mathrm{~nm}$, and analyzed using the FL-1 detector (FITC detector; $525 \mathrm{~nm}$ ) of a Beckman Coulter Epics XL flow cytometer (Becton-Dickinson, UK) and the CellQuest ${ }^{\mathrm{TM}}$ software.

Cell proliferation and inhibition assays. The effect of ICR62, NVP-AEW541, LY294002 and/or U0126 on the growth of human tumour cell lines was investigated using a colorimetric assay, as described previously (36). Briefly, tumour cells were seeded at a density of $5 \times 10^{3} /$ well in $100 \mu 1 \mathrm{DMEM}$ containing $2-10 \%$ FCS in a 96-well plate. Following 3-h incubation at $37^{\circ} \mathrm{C}, 100 \mu \mathrm{l}$ aliquots of the inhibitors were added to triplicate wells and the cells were incubated at $37^{\circ} \mathrm{C}$ until the cells in the wells containing control medium were confluent. Tumor cells were then fixed with glutaraldehyde, washed with tap water, air dried and stained with $0.05 \%$ methylene blue. The absorbance of each well was measured at $620 \mathrm{~nm}$ using a Labsystems MultiSkan RC plate reader (Thermo Electron Corporation, UK). To determine the initial number of cells, an extra plate of cells was set up and processed after 3 - $\mathrm{h}$ incubation at $37^{\circ} \mathrm{C}$ without the inhibitors.

Western blot analysis. Cells grown to near confluence in 6-well tissue culture plates (Greiner Bio-One, UK) were washed once and then incubated in $5 \mathrm{ml}$ DMEM/0.1\% FCS containing control medium, ICR62 (400 nM) and/or NVPAEW541 (400 nM) for $24 \mathrm{~h}$ at $37^{\circ} \mathrm{C}$, prior to no treatment or the addition of $10 \mathrm{nM}$ EGF, HB-EGF (R\&D Systems), IGF-I or IGF-II (Austral Biologicals) for $15 \mathrm{~min}$ at $37^{\circ} \mathrm{C}$. Cells were washed with PBS and then solubilized with $400 \mu 1$ of LDS sample buffer (Invitrogen, UK) supplemented with $4 \mu 1$ of protein inhibitor cocktail containing $104 \mathrm{mM}$ AEBSF, $80 \mu \mathrm{M}$ aprotinin, $2 \mathrm{mM}$ leupeptin, $4 \mathrm{mM}$ bestatin, $1.5 \mathrm{mM}$ pepstatin A, and $1.4 \mathrm{mM}$ E-64 (Sigma-Aldrich). The cell lysates were heated at $72^{\circ} \mathrm{C}$ for $10 \mathrm{~min}$ and their viscosity was reduced by several passages through a $25 \times 5 / 8$ gauge needle. Equal amounts of cell lysate were separated on $4-12 \%$ Bis-Tris-gels (Invitrogen) using the XCell II ${ }^{\mathrm{TM}}$ Surelock $^{\mathrm{TM}}$ Mini-Cell system (Invitrogen) and transferred to PVDF membranes using the XCell II ${ }^{\mathrm{TM}}$ Mini-Cell Blot Module kit (Invitrogen). The PVDF membranes were blocked to prevent non-specific binding, incubated with primary antibody for 


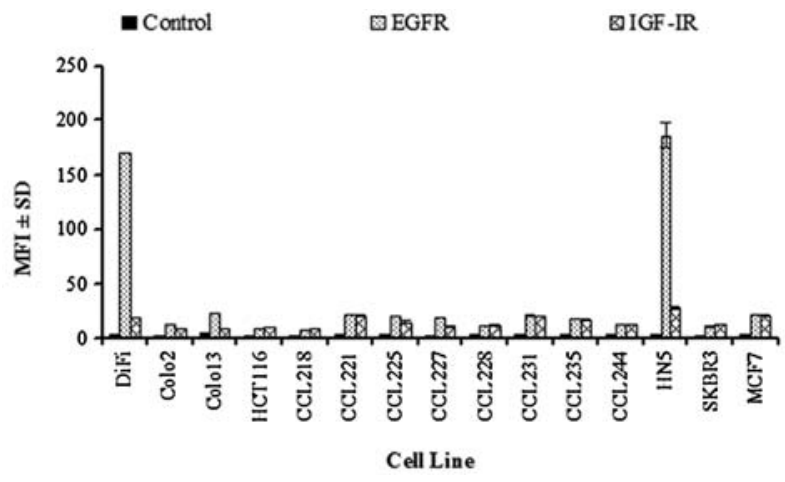

Figure 1. The cell surface expression of EGFR and IGF-IR on a panel of human colorectal tumour cell lines. Approximately $1 \times 10^{6}$ tumour cells were incubated for $1 \mathrm{~h}$ at $4^{\circ} \mathrm{C}$ with control medium or $10 \mu \mathrm{g} / \mathrm{ml}$ of antibodies to the external domain of the EGFR (HM43.16B) or IGF-IR (Calbiochem). Tumour cells were incubated with FITC-conjugated secondary antibody and 10,000 events were recorded and analyzed for growth factor receptor expression as described in Materials and methods. The data are presented as Mean Fluorescence Intensity $(\mathrm{MFI}) \pm \mathrm{SD}$

$1 \mathrm{~h}$ at room temperature. Specific signals were detected using the WesternBreeze ${ }^{\circledR}$ chemiluminescent anti-rabbit and antimouse kits (Invitrogen).

\section{Results}

Expression of EGFR and IGF-IR in human colorectal cancer cells. The expression levels of EGFR and IGF-IR in the panel of human colorectal cell lines used in this study were determined using FACS analysis. As shown in Fig. 1, among the human colorectal cancer cell lines, DiFi cells express the highest levels of EGFR, with a mean fluorescence intensity (MFI) of 169.6, but the value of EGFR expression ranged from only 8.4 (CCL 218) to 23.0 (Colo13) in the other 11 colorectal tumour cell lines. While all cell lines were positive for IGF-IR expression, the expression level was generally low in the panel of colorectal cancer cell lines, ranging from an MFI of 9.0 (Colo13) to 20.3 (CCL221) (Fig. 1).

Response of human colorectal cancer cells to treatment with NVP-AEW541. The IGF-IR-expressing control cell lines MCF-7 and HN5 were found to be highly sensitive to NVPAEW541. At $500 \mathrm{nM}$, NVP-AEW541 inhibited the growth of $\mathrm{MCF}-7$ by $80 \%\left(\mathrm{IC}_{50}=123 \mathrm{nM}\right)$, and $\mathrm{HN} 5$ cells by $54 \%$ $\left(\mathrm{IC}_{50}=470 \mathrm{nM}\right.$ ), respectively (Fig. 2A). However, of the 12 human colorectal cancer cells examined, only colo13, CCL218 and CCL235 were sensitive to treatment with NVP-AEW541 (Fig. 2B). For example, at $500 \mathrm{nM}$, NVP-AEW541 inhibited the growth of CCL218 cells by $67 \%\left(\mathrm{IC}_{50}=426 \mathrm{nM}\right.$ ) (Fig. $2 \mathrm{~A}$ ). No clear correlation was found between the levels of IGF-IR expression determined by FACS analysis (Fig. 1) and responses to NVP-AEW541 (Fig. 2B).

Effect of combination treatment with NVP-AEW541 and ICR62. In contrast to NVP-AEW541 treatment, by which CCL218 and CCL235 were found to be the most sensitive colorectal tumour cell lines (Fig. 2B), the EGFR-overexpressing cell line DiFi was the only colorectal tumour cell line that was highly sensitive to anti-EGFR mAb
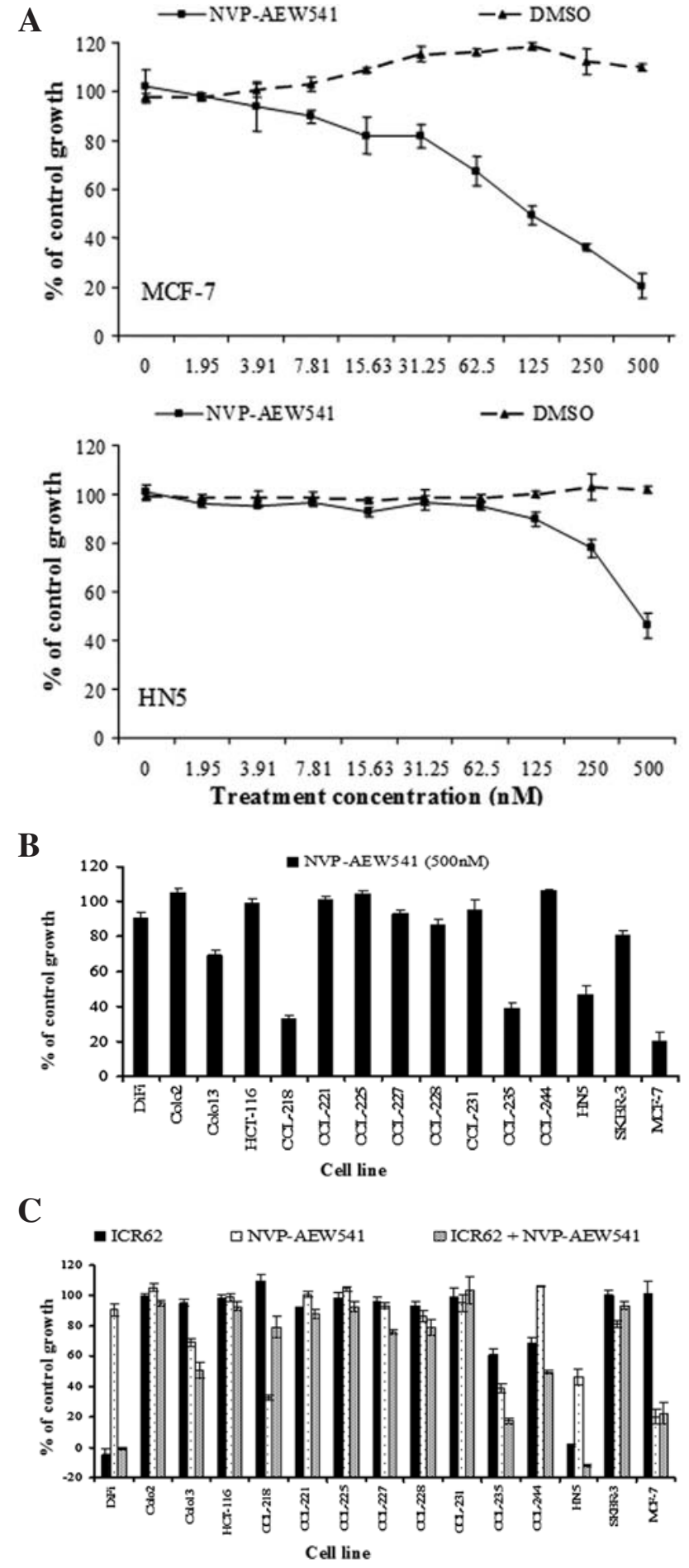

Figure 2. The effect of NVP-AEW541 and/or mAb ICR62 on the growth of human colorectal tumour cells. Tumour cells were grown in DMEM/2\%FCS containing control medium, mAb ICR62 (100 nM) and/or NVP-AEW541 $(500 \mathrm{nM})$, until cells in wells containing control medium were confluent. The effect of doubling dilutions of NVP-AEW541 on the growth of the 2 IGF-IR positive control tumour cell lines (MCF-7 and HN5) which were sensitive to this inhibitor (A) and the highest tested concentration of NVPAEW541 alone (B) and in combination with ICR62 (C) on the growth of all human colorectal tumour and positive control cells are shown. Tumour cell proliferation was calculated as a percentage of control cell growth, as described in Materials and methods. Each point represents the mean \pm SD of triplicate values.

ICR62 (Fig. 2C). Complete growth inhibition of DiFi cells by mAb ICR62 was achieved at a concentration of $3.2 \mathrm{nM}$ 


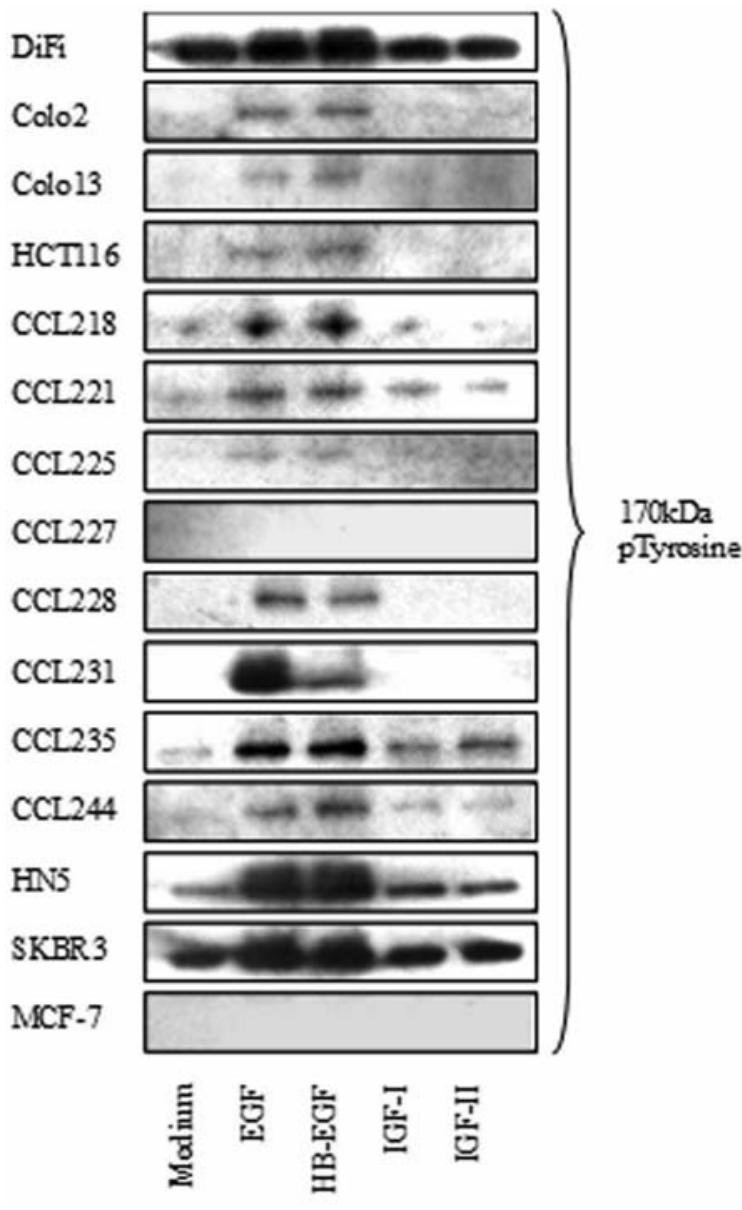

Figure 3. The effects of EGFR and IGF-IR ligand on EGFR phosphorylation. Human tumour cells were incubated in DMEM/0.1\% FCS for $1 \mathrm{~h}$ at $37^{\circ} \mathrm{C}$ prior to the addition of $10 \mathrm{nM}$ EGF, HB-EGF, IGF-I, or IGF-II for $15 \mathrm{~min}$ at $37^{\circ} \mathrm{C}$. The treated cells were lyzed and equal amounts of cell lysate were separated by SDS-PAGE, transferred to PVDF membranes, and probed with antibodies specific for the EGFR and total cellular phosphotyrosine.

$\left(\mathrm{IC}_{50}=0.52 \mathrm{nM}\right.$; data not shown $)$. We next investigated the effect of combination treatment with the EGFR and IGF-IR inhibitors on the growth of these tumour cells, and found that treatment with a combination of NVP-AEW541 and mAb ICR62 achieved better growth inhibition of Colo13, CCL227, CCL235 and CCL244 cells, compared with the result by either inhibitor alone. Interestingly, the combination treatment was found to be antagonistic in the case of CCL218 cells (Fig. 2C), and similar antagonistic results were found when NVP-AEW541 was used in combination with small molecules EGFR inhibitors in CCL218 cells (data not shown).

Phosphorylation of EGFR by stimulation with EGF, HB$E G F, I G F-I$ and $I G F-I I$. We found no clear correlation between cell surface expression levels of EGFR and IGF-IR in colorectal cancer cells and their response to the combination of EGFR and IGF-IR inhibitors. We next determined the levels of phosphorylated EGFR in these cell lines to determine whether the IGF-IR ligands are capable of transactivating the EGFR. Compared to DiFi cells, other human colorectal cell lines contained low or undetectable levels of EGFR (Fig. 3). In DiFi cells, EGFR phospho-

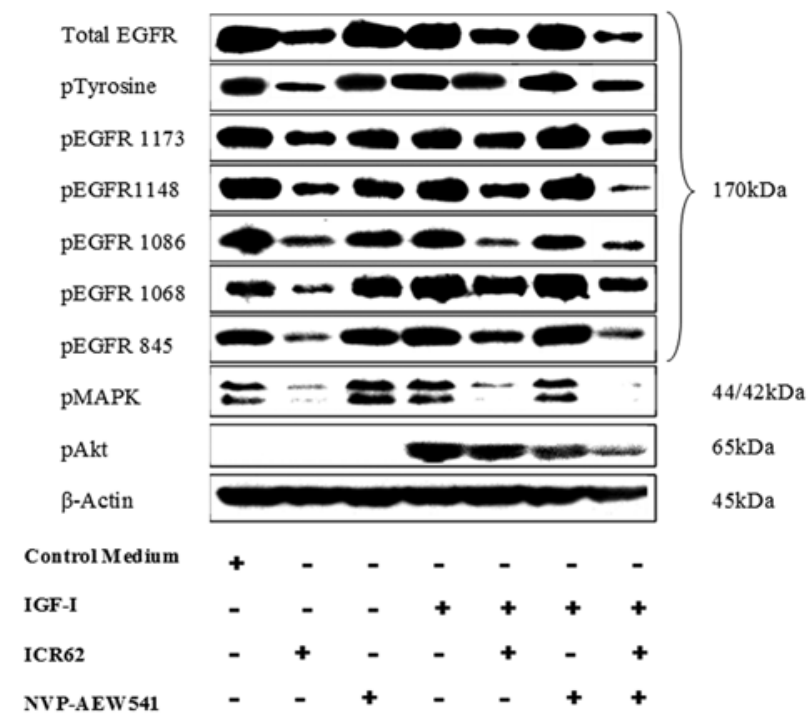

Figure 4. The phosphorylation status of EGFR, MAPK and Akt in DiFi cells treated with anti-EGFR mAb and/or IGF-IR TKI. DiFi cells were grown to near confluence in DMEM containing 10\% FCS, then treated in DMEM/ $0.1 \%$ FCS containing mAb ICR62 (400 nM), and/or NVP-AEW541 (400 nM) for $24 \mathrm{~h}$ at $37^{\circ} \mathrm{C}$. Cells were then incubated with no growth factor (control medium) or $10 \mathrm{nM}$ IGF-I for $15 \mathrm{~min}$ at $37^{\circ} \mathrm{C}$. The treated cells were lyzed and equal amounts of cell lysate were separated by SDS-PAGE, transferred to PVDF membranes, and probed with antibodies specific for the molecule of interest. The results are representative of at least 2 independent experiments.

rylation was further increased following stimulation with EGF or HB-EGF, but not with the IGF-IR ligands IGF-I and IGF-II. Interestingly, in the EGFR and IGF-IR dual positive CCL235 cell line, exposure of the cells to IGF-I or IGF-II induced trasns-phosphorylation of the EGFR (Fig. 3). Similar finding was observed in the EGFR-overexpressing control cell line HN5 but not in the EGFR-low expressing cell line MCF-7 or in the other human colorectal cell lines. The IGF-IR ligands were found to be less effective than EGF and HB-EGF at inducing tyrosine phosphorylation of the EGFR at the time-points studied (Fig. 3).

Effects of ICR62 and NVP-AEW541 on the phosphorylation levels of EGFR, MAPK and Akt in DiFi cells. Fig. 4 shows that DiFi cells contain a high basal level of phosphorylation at all 5 known distinct tyrosine residues on the EGFR, as well as phosphorylated MAPK p44/p42, but not that of Akt. ICR62 treatment of DiFi cells reduced the levels of total EGFR, phosphorylated EGFR levels at the 5 distinct tyrosine residues, and phosphorylated MAPK p44/p42 in the cells. In contrast, such results were not found upon NVP-AEW541 treatment (Fig. 4). However, NVP-AEW541 was effective in preventing IGF-I-stimulated phosphorylation of MAPK p44/p42 and Akt in DiFi cells, and such effects were more evident when NVP-AEW541 was used in combination with ICR62 (Fig. 4).

Growth response of human colorectal tumour cells following treatment with inhibitors of MEK and/or PI3-K. To assess their response to agents directly targeting the PI3K or MEK pathways, we determined the effect of a PI3K inhibitor, 

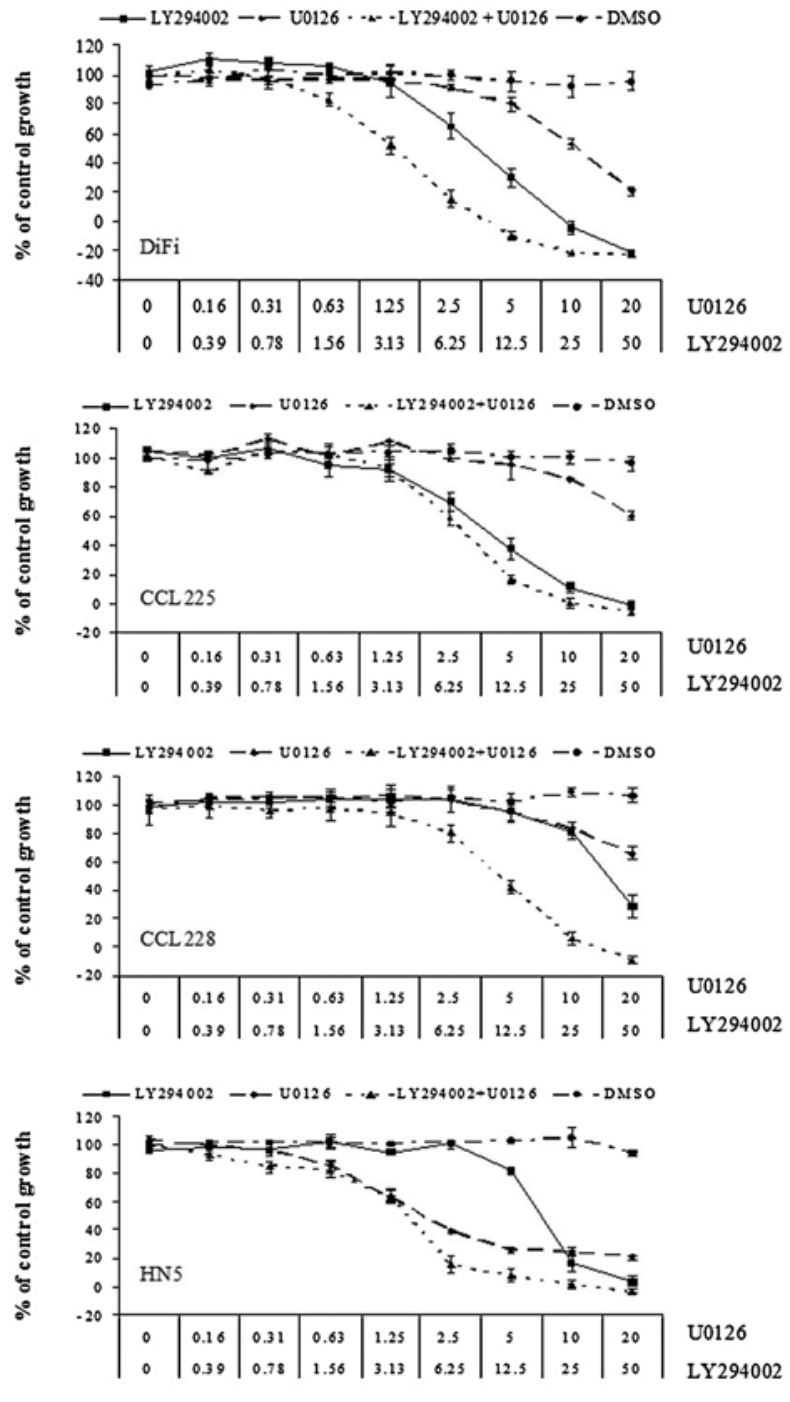

Treatment concentration $(\mathrm{nM})$

Figure 5. The effect of U0126 and/or LY294002 on the growth of tumour cells sensitive (DiFi, HN5) and resistant (CCL225, CCL228) to the EGFR inhibitors. Tumour cells were grown in DMEM/2\%FCS containing control medium, U0126 and/or LY294002 until cells in wells containing control medium were confluent. Tumour cell proliferation was calculated as a percentage of control cell growth, as described in Materials and methods. Each point represents the mean \pm SD of triplicate values.

LY294002 and, a MEK inhibitor, U0126, on the proliferation of cell lines that were found to be sensitive (DiFi, HN5) or resistant (CCL225, CCL228) to ICR62 and/or NVPAEW541. Fig. 5 shows that DiFi, HN5, CCL225, and CCL228 were all sensitive to LY294002 or U0126 treatment. At $50 \mu \mathrm{M}$, LY294002 inhibited completely the growth of DiFi, CCL225, and HN5 cells and growth of CCL228 cells by $72 \%$ (Fig. 5). At $20 \mu \mathrm{M}$, the MEK inhibitor U0126 inhibited the growth of DiFi, CCL225, CCL228, and HN5 cells by $81,39,33$ and $79 \%$, respectively (Fig. 5). Using a combination of the 2 inhibitors, there was increased growth inhibition in each of the cell lines when compared to treatment with either single agent (Fig. 5). The findings suggest that the lack of response to ICR62 or NVP-AEW541 in resistant cell lines, such as CCL225 and CCL228, was due to EGFR or IGF-IR independent activation of these downstream signal pathways.

\section{Discussion}

In recent years, several EGFR inhibitors have been approved by the FDA for the treatment of cancer patients $(40,41)$. Of these, anti-EGFR mAbs cetuximab and panitumumab were approved for the treatment of patients with metastatic colorectal cancer (42). Despite positive responses observed in approximately $10-20 \%$ of patients treated, a major obstacle is the lack of overall response of colorectal cancer to therapy with the anti-EGFR mAbs. In addition, there are currently no reliable markers for response to therapy with the EGFR inhibitors. In several experimental studies, co-expression of the IGF-IR has been associated with resistance to treatment with anti-EGFR and anti-HER-2 therapies and co-targeting the IGF-IR and EGFR or HER-2 with a combination of the 2 agents inhibiting respective targets has shown advantages of therapeutic effect over the single inhibitor alone (27,31-33). Consistent with these findings, in the present study, we found co-expression of the EGFR and IGF-IR in a fraction of human colorectal cancer cell lines and potential therapeutic advantage of co-targeting the EGFR and IGF-IR with an antiEGFR mAb (ICR62) and an IGF-IR TKI (NVP-AEW541).

Of the 12 human colorectal cancer cell lines examined, only DiFi expressed high levels of the EGFR (Fig. 1) and was the only human colorectal tumour cell line that was highly sensitive to the anti-EGFR mAb ICR62 (Fig. 2C). In addition, there was no clear association between the levels of phosphorylated EGFR in the panel of colorectal cancer cells and response to the anti-EGFR mAb ICR62. For example, unlike DiFi or HN5 cells which contained high levels of pEGFR and were highly sensitive to ICR62 treatment, this antibody did not inhibit the growth of SKBR3 cells which like DiFi and HN5 cells contained high level of pEGFR (Figs. 2C and 3). In addition, while all of the colorectal cancer cell lines were IGF-IR positive, the levels of IGF-IR expression were not predictive of sensitivity/ resistance to the EGFR inhibitors. Interestingly, NVPAEW541 in combination with ICR62 was found to be more effective at inhibiting the growth of some human colorectal cancer cell lines (e.g. Colo13, CCL235, CCL244) than either agent alone. Others have reported enhanced antitumour activity in human breast and prostate cancer cell models when an IGF-IR TKI was used in combination with antiEGFR or anti-HER-2-based therapies (2,31). More recently, Hopfner and colleagues have also reported that NVP-AEW541 in combination with anti-EGFR mAb cetuximab was more effective than treatment with either agent alone at inhibiting the growth of 2 human colorectal tumour cell lines, HCT116 and HT29 (43). Similar to responses achieved with either single treatment, no clear association was found between EGFR or IGF-IR expression and response to the combination of NVP-AEW541 and ICR62 in our study. Interestingly, of the 12 human colorectal tumour cell lines used in the present study, both IGF-I and IGF-II induced tyrosine phosphorylation of the EGFR in several cell lines. This was more evident in CCL235 cells, which were also growth inhibited by the greatest extent by the combination of EGFR and IGF-IR inhibitors (Fig. 3).

While the combination of the EGFR and IGF-IR inhibitors did not completely inhibit the growth of any colorectal 
tumour cell line in this study (Fig. 2C), the growth of tumour cells resistant to the EGFR and/or IGF-IR inhibitors could be inhibited using inhibitors of the MEK/MAPK (U0126) and/or PI3-K/Akt (LY294002) pathways (Fig. 4). These data are consistent with a previous study in which the EGFR TKI gefitinib was shown to be more effective than inhibitors of the PI3-K and MAPK pathways at inhibiting the growth of EGFR overexpressing A431 cells (44). Therefore, taken together, these results suggest that in EGFR overexpressing tumour cells (e.g. DiFi, HN5, A431), such tumour cells are likely to be dependent upon the EGFR for their proliferation and survival and that EGFR inhibition is more effective than PI3-K and MEK inhibition $(34,45)$. In contrast, in other cell lines which expressed low levels of EGFR and IGF-IR (Fig. 1), direct inhibition of the MAPK and PI3-K pathways may be superior to targeting with the EGFR and/or IGF-IR inhibitors as such cells may rely on alternative/multiple receptors for activation of the MAPK or PI3-K pathways $(44,46,47)$.

In a previous study, IGF-I was shown to delay the occurrence of apoptosis induced by anti-EGFR mAb cetuximab in DiFi cells but the protection was not sustained with the expansion of treatment due to the high sensitivity of the cells to cetuximab (48). Similarly, we found in our current study that IGF-I or IGF-II failed to protect DiFi cells from ICR62-mediated growth inhibition in extended cell culture. This was in contrast to our as-yet-unpublished data using 6 different EGFR ligands that protected DiFi cells from ICR62-induced growth inhibition (data not shown). In addition, either stimulation of IGF-IR with ligand or inhibition of the receptor with NVP-AEW541 had no major effect on phosphorylation levels of EGFR or MAPK p44/p42 in DiFi cells. While the anti-EGFR mAb ICR62 was able to attenuate basal and IGF-stimulated phosphorylation of MAPK p44/p42, it did not prevent IGF-I-induced phosphorylation of Akt in DiFi cells. Because IGF-I induced Akt phosphorylation was decreased by NVP-AEW541 and more effectively when used in combination with ICR62, the results suggest that the combination of EGFR and IGF-IR inhibitors may have potential for enhanced inhibition on selective signal transducing molecules (i.e. Akt) in colorectal cancer cells.

The lack of apparent additive or synergistic growth inhibition of DiFi cells with the combination of NVPAEW541 and ICR62 is likely due largely to high sensitivity of the cells to EGFR inhibition alone, which may underestimate the potential utility of combinatorial therapy against the 2 receptors. We have shown recently that co-expression of IGF-IR and EGFR is common in patients with colorectal cancer (17). In addition to its role in up-regulating the EGFR autocrine loop and in mediating resistance to the EGFR inhibitors, IGF-I has also been shown to up-regulate the production of VEGF in several types of human cancers, including colorectal cancer $(25,32,33)$. Moreover, we have shown previously that mAb ICR62, although not being able to inhibit the growth of cells expressing the type-III deletion mutant EGFR (EGFRvIII) in cell culture, has strong activity in inhibiting the metastasis of EGFRvIII expressing cells to the lung in athymic mice through mediating antibody-dependent cellular cytotoxicity (ADCC) (49). Thus, there might be additional antitumor effects of the combination of ICR62 and NVP-AEW541 mediated via immuno- logical mechanisms such as ADCC, or via disturbing tumour blood supply that certainly warrants further investigation $(47,49,50)$. It will also be interesting to determine whether the combination of NVP-AEW541 and ICR62 produces an antagonistic effect against CCL218 cells in vivo.

In summary, our results show that combinatorial treatment with the anti-EGFR mAb ICR62 and IGF-IR TKI NVPAEW541 resulted in an enhanced growth inhibition in a fraction of colorectal cancer cell lines. Since co-expression of the EGFR, HER-2 and IGF-IR is common in patients with Dukes' C colorectal cancer (17), further in-depth studies are warranted to elucidate the full therapeutic potential of combining the EGFR and IGF-IR inhibitors in experimental colorectal cancer models and the human setting.

\section{Acknowledgements}

We are grateful to Novartis for providing the IGF-IR tyrosine kinase inhibitor NVP-AEW541, and the GUTS charity (UK) for supporting this work.

\section{References}

1. Parkin DW: Global cancer statistics in the year 2000. Lancet Oncol 2: 533-543, 2001.

2. Jones JI and Clemmons DR: Insulin-like growth factors and their binding proteins: biological actions. Endocr Rev 16: 3-34, 1995.

3. LeRoith D and Roberts CT: The insulin like growth factor system and cancer. Cancer Lett 195: 127-137, 2003.

4. Baserga R: Targeting the IGF-1 receptor: from rags to riches. Eur J Cancer 40: 2013-2015, 2004

5. Butler AA, Yakar S, Gewolb IH, Karas M, Okubo Y and LeRoith D: Insulin-like growth factor-I receptor signal transduction: at the interface between physiology and cell biology. Comp Biochem Physiol B Biochem Mol Biol 121: 19-26, 1988.

6. Blakesley VA, Scrimgeour A, Esposito D and LeRoith D: Signaling via the insulin-like growth factor-I receptor: does it differ from insulin receptor signaling? Cytokine Growth Factor Rev 7: 153-159, 1996.

7. Valentinis B and Baserga R: The IGF-I receptor protects tumour cells from apoptosis induced by high concentrations of serum. Biochem Biophys Res Commun 224: 362-368,1996.

8. Rubini M, Hongo A, D'Ambrosio C and Baserga R: The IGF-I receptor in mitogenesis and transformation of mouse embryo cells: role of receptor number. Exp Cell Res 230: 284-292, 1997.

9. Perer ES, Madan AK, Shurin A, et al: Insulin-like growth factor I receptor antagonism augments response to chemoradiation therapy in colon cancer cells. J Surg Res 94: 1-5, 2000.

10. Peretz S, Kim C, Rockwell S, Baserga R and Glazer PM: IGF1 receptor expression protects against microenvironmental stress found in the solid tumour. Radiat Res 158: 174-180, 2002.

11. Reinmuth N, Fan F, Liu W, et al: Impact of insulin-like growth factor receptor-I function on angiogenesis, growth and metastasis of colon cancer. Lab Invest 82: 1377-1389, 2002.

12. Sekharam M, Zhao H, Sun M, et al: Insulin-like growth factor 1 receptor enhances invasion and induces resistance to apoptosis of colon cancer cells through the Akt/Bcl-x(L) pathway. Cancer Res 63: 7708-7716, 2003

13. Hakam A, Yeatman TJ, Lu L, et al: Expression of insulin-like growth factor-1 receptor in human colorectal cancer. Hum Pathol 30: 1128-1133, 1999.

14. Weber MM, Fottner C, Liu SB, Jung MC, Engelhardt D and Baretton GB: Overexpression of the insulin-like growth factor I receptor in human colon carcinomas. Cancer 95: 2086-2095, 2002.

15. Ouban A, Muraca P, Yeatman T and Coppola D: Expression and distribution of insulin-like growth factor-1 receptor in human carcinomas. Hum Pathol 34: 803-808, 2003.

16. Peters G, Gongoll S, Langner C, et al: IGF-1R, IGF-1 and IGF-2 expression as potential prognostic and predictive markers in colorectal-cancer. Virchows Arch 443: 139-145, 2003. 
17. Cunningham MP, Essapen S, Thomas H, Green M, Lovell DP, Topham C, Marks C and Modjtahedi H: Coexpression of the IGF-IR, EGFR, and HER-2 is common in colorectal cancer patients. Int J Oncol 28: 329-335, 2006.

18. Hailey J, Maxwell E, Koukouras K, Bishop WR Pachter JA and Wang Y: Neutralizing anti-insulin-like growth factor receptor 1 antibodies inhibit receptor function and induce receptor degradation in tumour cells. Mol Cancer Ther 1: 1349-1353, 2002.

19. Jackson-Booth PG, Terry C, Lackey B, Lopaczynska M and Nissley P: Inhibition of the biologic response to insulin-like growth factor I in MCF-7 breast cancer cells by a new monoclonal antibody to the insulin-like growth factor-I receptor. The importance of receptor down-regulation. Horm Metab Res 35: 850-856, 2003.

20. Maloney EK, McLaughlin JL, Dagdigian NE, et al: An antiinsulin-like growth factor I receptor antibody that is a potent inhibitor of cancer cell proliferation. Cancer Res 63: 5073-5083, 2003.

21. Mitsiades CS, Mitsiades NS, McMullan CJ, et al: Inhibition of the insulin-like growth factor receptor-1 tyrosine kinase activity as a therapeutic strategy for multiple myeloma, other hematologic malignancies and solid tumors. Cancer Cell 5: 221-230, 2004.

22. Goetsch L, Gonzalez A, Leger O, et al: A recombinant humanized anti-insulin-like growth factor receptor type I antibody (h7C10) enhances the antitumor activity of vinorelbine and anti-epidermal growth factor receptor therapy against human cancer xenografts. Int J Cancer 113: 316-328, 2005.

23. Min Y, Adachi Y, Yamamoto $\mathrm{H}$, et al: Insulin-like growth factor I receptor blockade enhances chemotherapy and radiation responses and inhibits tumour growth in human gastric cancer xenografts. Gut 54: 591-600, 2005.

24. Miyamoto S, Nakamura M, Shitara K, et al: Blockade of paracrine supply of insulin-like growth factors using neutralizing antibodies suppresses the liver metastasis of human colorectal cancers. Clin Cancer Res 11: 3494-3502, 2005.

25. Warren RS, Yuan H, Matli MR, Ferrara N and Donner DB: Induction of vascular endothelial growth factor by insulin-like growth factor 1 in colorectal carcinoma. J Biol Chem 271: 29483-29488, 1996.

26. Liu B, Fang M, Lu Y, Mendelsohn J and Fan Z: Fibroblast growth factor and insulin-like growth factor differentially modulate the apoptosis and G1 arrest induced by anti-epidermal growth factor receptor monoclonal antibody. Oncogene 20: 1913-1922, 2001

27. Chakravarti A, Loeffler JS and Dyson NJ: Insulin-like growth factor receptor I mediates resistance to anti-epidermal growth factor receptor therapy in primary human glioblastoma cells through continued activation of phosphoinositide 3-kinase signaling. Cancer Res 62: 200-207, 2002.

28. Adams TE, McKern NM and Ward CW: Signalling by the type 1 insulin-like growth factor receptor: interplay with the epidermal growth factor receptor. Growth Factors 22: 89-95, 2004

29. Wang D, Patil S, Li W, Humphrey LE, Brattain MG and Howell GM: Activation of the TGFalpha autocrine loop is downstream of IGF-I receptor activation during mitogenesis in growth factor dependent human colon carcinoma cells. Oncogene 21: 2785-2796, 2002

30. Ahmad T, Farnie, G, Bundred NJ and Anderson NG: The mitogenic action of insulin-like growth factor I in normal human mammary epithelial cells requires the epidermal growth factor receptor tyrosine kinase. J Biol Chem 279: 1713-1719, 2004.

31. Lu Y, Zi X, Zhao Y, Mascarenhas D and Pollak M: Insulin-like growth factor-I receptor signaling and resistance to trastuzumab (Herceptin). J Natl Cancer Inst 93: 1852-1857, 2001.

32. Jones HE, Goddard L, Gee JM, et al: Insulin-like growth factor-I receptor signalling and acquired resistance to gefitinib (ZD1839; Iressa) in human breast and prostate cancer cells. Endocr Relat Cancer 11: 793-814, 2004.

33. Camirand A, Zakikhani M, Young F and Pollak M: Inhibition of insulin like growth factor-1 receptor signaling enhances growthinhibitory and proapoptotic effects of gefitinib (Iressa) in human breast cancer cells. Breast Cancer Res 7: 570-579, 2005.
34. Cunningham MP, Thomas $\mathrm{H}$, Fan $\mathrm{Z}$ and Modjtahedi $\mathrm{H}$ Responses of human colorectal tumour cells to treatment with anti-epidermal growth factor receptor antibody ICR62 used alone or in combination with the EGFR tyrosine kinase inhibitor gefitinib. Cancer Res 66: 7708-7715, 2006.

35. Garcia-Echeverria C, Pearson MA, Marti A, et al: In vivo antitumor activity of NVP-AEW541 - A novel, potent and selective inhibitor of the IGF-IR kinase. Cancer Cell 5: 231-239, 2004.

36. Modjtahedi H, Styles JM and Dean CJ: The human EGF receptor as a target for cancer therapy: six new rat mAbs against the receptor on the breast carcinoma MDA-MB 468 . Br J Cancer 67: 247-253, 1993.

37. Gross ME, Zorbas MA, Danels YJ, et al: Cellular growth response to epidermal growth factor in colon carcinoma cells with an amplified epidermal growth factor receptor derived from a familial adenomatous polyposis patient. Cancer Res 51: 1452-1459, 1991

38. Guvakova MA and Surmacz E: Overexpressed IGF-I receptors reduce estrogen growth requirements, enhance survival, and promote E-cadherin-mediated cell-cell adhesion in human breast cancer cells. Exp Cell Res 231: 149-162, 1997.

39. Lewis GD, Figari I, Fendly B, et al: Differential responses of human tumor cell lines to anti-p185HER2 monoclonal antibodies. Cancer Immunol Immunother 37: 255-263, 1993.

40. Mendelsohn J and Baselga J: Status of epidermal growth factor receptor antagonists in biology and treatment of cancer. J Clin Oncol 21: 2787-2799, 2003.

41. Rocha-Lima CM, Soares HP, Raez LE and Singal R: EGFR targeting of solid tumours. Cancer Control 14: 295-304, 2007.

42. Ng K and Zhu AX: Targeting the epidermal growth factor receptor in metastatic colorectal cancer. Crit Rev Oncol Hematol 65: 8-20, 2008.

43. Hopfner M, Sutter AP, Huether A, Baradari V and Scherubl H Tyrosine kinase of insulin growth factor receptor as target for novel treatment and prevention strategies of colorectal cancer. World J Gastroenterol 12: 5635-5643, 2006.

44. Janmaat ML, Kruyt FA, Rodriguez JA and Giaccone G: Response to epidermal growth factor receptor inhibitors in non-small cell lung cancer cells: limited antiproliferative effects and absence of apoptosis associated with persistent activity of extracellular signal-regulated kinase or Akt kinase pathways. Clin Cancer Res 9: 2316-2326, 2003.

45. Albanell J, Codony-Servat J, Rojo F, et al: Activated extracellular signal-regulated kinases: association with epidermal growth factor receptor/transforming growth factor alpha expression in head and neck squamous carcinoma and inhibition by anti-epidermal growth factor receptor treatments. Cancer Res 61: 6500-6510, 2001.

46. Arteaga CL: Epidermal growth factor receptor dependence in human tumors: more than just expression? Oncologist 7: 31-39, 2002.

47. Tortora G, Bianco R, Daniele G, Ciardiello F, McCubrey JA, Ricciardi MR, Ciuffreda L, Cognetti F, Tafuri A and Milella M: Overcoming resistance to molecularly targeted anticancer therapies: rational drug combinations based on EGFR and MAPK inhibition for solid tumours and haematologic malignancies. Drug Resist Updat 10: 81-100, 2007

48. Wu X, Fan Z, Masui H, Rosen N and Mendelsohn J: Apoptosis induced by an anti-epidermal growth factor receptor monoclonal antibody in a human colorectal carcinoma cell line and its delay by insulin. J Clin Invest 95: 1897-1905, 1995.

49. Modjtahedi H, Moscatello DK, Box G, et al: Targeting of cells expressing wild-type EGFR and type-III mutant EGFR (EGFRvIII) by anti-EGFR MAb ICR62: a two-pronged attack for tumour therapy. Int J Cancer 105: 273-2780, 2003.

50. Viloria-Petit, Crombet T, Jothy S, Hicklin D, Bohlen P, Schaeppi JM, Rak J and Kerbel RS: Acquired Resistance to the antitumour effect of epidermal growth factor receptorblocking antibodies in vivo: a role for altered tumour angiogenesis. Cancer Res 61: 5090-5101, 2001. 